\title{
Acute Renal Failure Due to the Giant Villous Adenoma of Colon: McKittrick-Wheelock Syndrome
}

\section{Kolonun Dev Villöz Adenomuna Bağlı Akut Böbrek Yetmezliği: McKittrick-Wheelock Sendromu}

\author{
Ebru Esen ${ }^{1}$, Ramazan Saygın Kerimoğlu ${ }^{1}$ \\ ${ }^{1}$ Konya Eğitim ve Araştırma Hastanesi, Genel Cerrahi Kliniği, Konya, Türkiye
}

Dergiye Ulaşma Tarihi: 06.01.2019 Dergiye Kabul Tarihi: 26.04.2019 Doi: 10.5505/aot.2019.38991

\section{ÖZET}

Kolonun malign tümörleri genellikle benign adenomlardan köken almaktadırlar. Büyük boyutlu ve villöz komponenti olan adenomların malignleşme potansiyelleri diğer adenomlara göre daha fazladır. Adenomlar genellikle asemptomatikdirler ancak boyutları arttıkça kanama, tenesmus, obstruksiyon, intusepsiyon gibi semptomlara neden olabilirler. Villöz adenomların bir kısmını oluşturan sekretuar adenomlara bağlı mukuslu diare görülebilir. Sekretuar adenomlar genellikle rektosigmoid bölgede yerleşir ve $4 \mathrm{~cm}$ 'den büyüktürler. McKittrickWheelock sendromu, rektal sekretuar villöz adenoma bağlı olarak gelişen; kronik mukuslu diare, renal yetmezlik ve elektrolit imbalansı triadı ile karşımıza çıkmaktadır. Literatürde yaklaşık olarak 100 civarında vaka bildirilmiştir. Sendroma sebep olan villöz adenom; büyük boyutu ve histolojik tipi nedeni ile invaziv kanser için yüksek risk taşımaktadır. Tedavi edilmediği taktirde metabolik kollaps ve malignite gibi yıkıcı sonuçları olan bu sendromun sekretuar diare ayırıcı tanıları arasında unutulmaması gerekmektedir. Erken tanı ve uygun tedavi ile hayat kalitesinde artma ve belirgin sağkalım avantajı sağlanabilir. Bu olgu sunumunda McKittrick-Wheelock sendromuna sebep olan en büyük boyutlu adenomlardan birinin tespit edildiği ve rektum kanseri tanısı alan bir hastanın bilgilerini sunmayı amaçladık.

Anahtar Kelimeler: Villöz adenom, Kronik diare, Akut böbrek yetmezliği, Elektrolit imbalansı, Rektal kanser

\begin{abstract}
Malignant tumors of the colon usually originate from benign adenomas. Adenomas with large size and villous component have higher malignancy potential than other adenomas. Adenomas are usually asymptomatic, but as their size increase, they may cause symptoms such as bleeding, tenesmus, obstruction, intussusception. Mucous diarrhea can be seen due to secretory adenomas that constitute the subgroup of villous adenomas. Secretory adenomas are usually located in the rectosigmoid region and are larger than $4 \mathrm{~cm}$. McKittrick-Wheelock syndrome is characterized by chronic mucous diarrhea, renal failure and electrolyte imbalance due to rectal secretory villous adenoma. Approximately 100 cases have been reported in the literature. Adenoma causing McKittrick Wheelock syndrome carries a high risk for the development of invasive cancer due to its big size and histologic sub-type. This syndrome can be fatal due to the metabolic collapse or possible malignancy however early diagnosis and proper treatment may increase quality of life and serve a significant survival advantage for the patients. The importance of being aware of McKittrick-Wheelock syndrome and the need to include this diagnosis in the work up of patients with secretory diarrhea should be highlighted.In this case report, we aimed to present a patient who was diagnosed with rectal cancer and was diagnosed as one of the largest adenomas causing McKittrick-Wheelock syndrome.
\end{abstract}

Keywords: Villous adenoma, Chronic diarrhea, Acute renal failure, Electrolyte imbalance, Rectal cancer

\section{GíRiș:}

Kolonun malign tümörleri genellikle benign adenom zemininde gelişmektedirler. Adenomların 10 y1l içinde kolon kanserine ilerleme riski \%2.5 olmakla birlikte büyük boyutlu ve villöz adenomlarda bu risk artmaktadir $(1,2)$. 
Tarama amaçlı yapılan kolonoskopilerin \%30'unda saptanan adenomlar kolon ve rektumun displastik ve premalign lezyonlarıdır. S1klıkla asemptomatik olmalarına rağmen büyümeleri ile birlikte kanama, tenesmus, prolapsus, intussepsiyon, obstruksiyon gibi semptomlara yol açabilirler (3). Mukuslu diare, villöz adenomların küçük bir bölümünü oluşturan sekretuar adenomlara bağlı olarak gelişebilen nadir bir semptomdur. Sekretuar adenomlar siklıkla rektosigmoid bölgede yerleşmekte, genellikle 4 cm'den büyük olmakta ve villöz adenomların \%2-3 'lük bir bölümünü olușturmaktadırlar $(2,4)$.

McKittrick-Wheelock sendromu 1954'te tanımlandığından beri, literatürde 100 civarında vaka sunulmuştur (3). Sekretuar diare, dehidratasyon, hiponatremi, hipokalemi, hipokloremi, prerenal akut böbrek yetmezliği ile karakterizedir ve sendroma sebep olan adenom genelikle dev boyutlardadır. McKittrick-Wheelock sendromu tedavi edilmediği taktirde ölümcül seyreder (5). McKittrick-Wheelock sendromu, rektal sekretuar villlöz adenoma bağlı olarak gelişen; kronik mukuslu diare, renal yetmezlik ve elektrolit imbalansı triadı ile karşımıza çıkan bir hastada ayırıcı tanıda akla gelmelidir.

$\mathrm{Bu}$ olgu sunumunda literatürde bugüne dek McKittrick-Wheelock sendromuna sebep olan en büyük boyutlu adenomlardan birinin tespit edildiği ve rektum kanseri tanısı alan bir hastanın bilgilerini sunmayı amaçladık.

\section{OLGU SUNUMU:}

Yetmişdört yaşında kadın hasta, baş dönmesi, kusma ve kanlı ishal şikayetleri ile acil servise başvurmuştu. Hikayesinde; son 5-6 yıldır günde 6-8 kez mukuslu, yumuşak kıvamlı dışkılama öyküsü olan hastanın, son başvuru öncesi yapılan muayene ve kolonoskopik değerlendirmesinde düşük dereceli displazi içeren villöz adenom tanısı konmuş ve hastaya cerrahi önerilmişti ancak hasta tedaviyi reddetmişti. Son iki aydır ishal şikayetine baş dönmesi, halsizlik ve kusma eklenmiş. Özgeçmişinde hipertansiyon ve kardiak ritm bozukluğu mevcut.

Başvuru muayenesinde; takipneik, mukoz membranlar kuru, oligoürik, halsiz ve düşkün görünümde idi. Vital bulguları: nabız: 115/dk taşikardik ve aritmik; tansiyon arteriel: $110 / 70 \mathrm{mmHg}$, solunum say1s1: $25 / \mathrm{dk}$, vücut sıcaklığı: 37.8 derece idi . Batın muayenesi hafif distansiyon haricinde normal; akciğer grafisinde plevral effüzyon; iki pozitif pretibial ödem mevcuttu. Rektal dijital muayenesinde anal kanaldan ekstrude olan ve anal girimden itibaren lümeni çepeçevre saran, posteriorda sert ancak genel olarak yumuşak; lümeni daraltan lezyon saptandi. Laboratuar tetkiklerinde venöz kan gazı değerleri: $\mathrm{PH}=7.305, \quad \mathrm{PCO} 2=33.9 \mathrm{mmHg}, \mathrm{PAO} 2=29.3$ $\mathrm{mmHg}, \mathrm{HCO} 3=16.5 \mathrm{mEq} / \mathrm{l}$, anyon gap $=21.5$ $\mathrm{mEq} / 1$, laktik asit $=1.63 \mathrm{mmol} / \mathrm{l}$ imiş. Beyaz küre $=19.0810^{3} / \mathrm{mm} 3$ (nötrofilik \%83), $\mathrm{Hb}=9.6$ $\mathrm{mg} / \mathrm{dl}$; biyokimyasal incelemede ise üre $=350$ $\mathrm{mg} / \mathrm{dl}$, kreatinin $=7.28 \mathrm{mg} / \mathrm{dl}$, potasyum $=3.35$ $\mathrm{mEq} / \mathrm{L}, \quad$ sodyum $=130 \mathrm{mEq} / \mathrm{L}$ ve klor $=100$ $\mathrm{mEq} / \mathrm{L}$ idi..

Hastanın yatışı sonrasında takipleri nefroloji uzmanı eşliğinde yapıldı. 72 saatte intravenöz hidrasyon, dializ ve antibiyotik ile metabolik dengesizlik normale yakın değerlere getirildi. Kolonoskopik incelemede anal kanaldan başlayıp $24 \mathrm{~cm}$ proksimale uzanan lümeni çepeçevre sararak daraltan, yer yer ülserovejetan görünümde yoğun sekresyonlu villöz polipoid yapı tesbit edildi (Resim 1). Çoklu biopsiler alındı. Biopsi sonucu yüksek dereceli villöz adenom ve intramukozal karsinom olarak raporland.

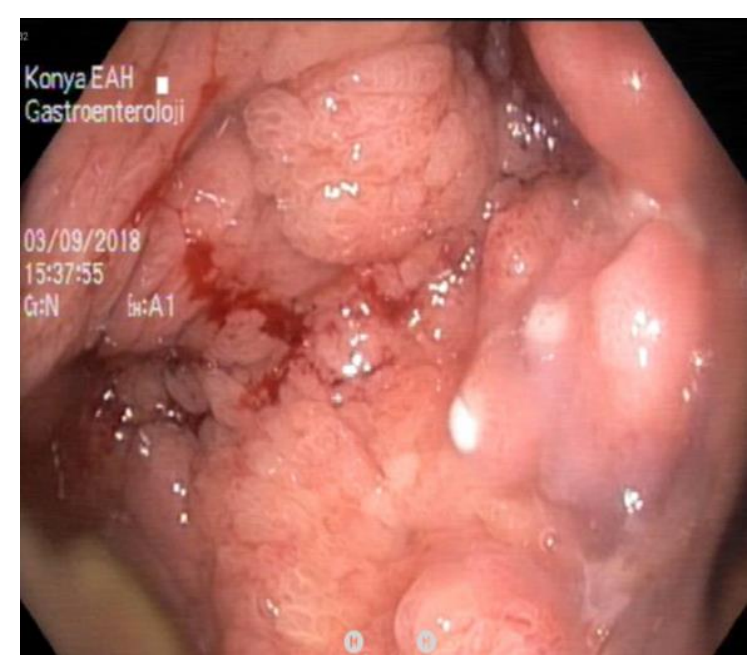

Resim 1. Dev Villöz Adenom Kolonoskopik Görüntü

Hastanın cerrahiyi kesinlikle reddetmesi nedeniyle radyoterapi planlamasi yapılmaya karar verilerek metastaz taraması amaciyla tüm vücut pozitron emisyon tomografi (PET/CT) çekildi. PET/CT'de sol akciğerde 5-16 mm arasi boyutta SUVmax: 4,38 olan metastatik nodüler lezyonlar ve anal kanaldan başlayıp sigmoid kolona kadar uzanan lümeni daraltan yaygın düzensiz duvar kalınlaşmasına sahip 
SUVmax: 18.84 olan ve perirektal SUVmax'1 6.94 olan birkaç adet lenf nodu izlendi.

Destek tedavi ile durumu stabil hale gelen hastanin diaresinin devam etmesi, hipopotasemisinin düzeltilememesi nedeniyle hasta ameliyatı kabul etti. Histopatolojik değerlendirme ve görüntüleme yöntemleri sonuçlarının malignite ile uyumlu olması; anal kanalın tamamen tutulması ve tümörün anal kanaldan ekstrude olması nedeniyle sfinkterlerin korunamayacağı öngörülerek; cerrahi yöntem olarak abdominoperineal rezeksiyon işlemi gerçekleştirildi (Resim 2,3).

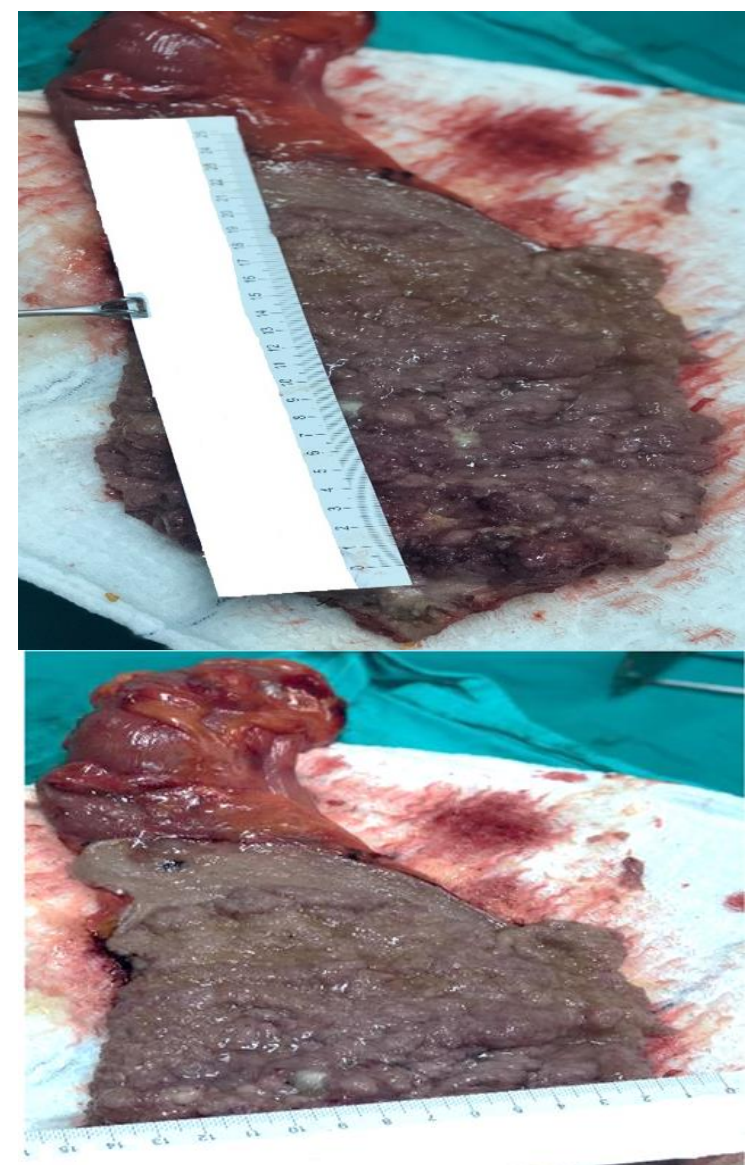

Resim 2, 3. Abdominoperineal Rezeksiyon Materyali

Postoperatif süreçte 3. gün plazma elektrolit değerleri düzeldi. Ek komplikasyon gelişmeyen hasta 5. gün taburcu edildi. Nihai patoloji "villöz adenom zemininde anal kanaldan başlayan $21 \mathrm{~cm}$ 'lik alanı anüler tarzda sarmış ve yaklaşı $7 \mathrm{~cm}$ 'lik segment boyunca uzanan T3N2 adenokanser ve diğer alanlarda ağır derecede displaziyle birlikte mukozal karsinoma in-situ odakları mevcuttur" olarak raporlandi. Medikal onkoloji tarafindan hastaya adjuvan kemoterapi başland. Postoperatif 4.ay kontrolünde hastanın stabil olduğu ve ek problemi olmadığı görüldü..

\section{TARTIŞMA}

Adenomlar kolorektumun displastik lezyonlarıdır. Tarama kolonoskopilerinin $\% 30$ 'unda saptanırlar ve \%4-40 oranında malignleşirler. Şiddetli displazi, invaziv kanser için en yüksek riski taşımaktadır. En yüksek malignleşme oranları villöz adenomlardadır (19). Adenomların malignleşmesi artan yaş, sayı ve boyutun yanı sıra kolorektumda yerleşim yerine de bağlıdır. En sık malignleşen adenomlar sol kolon ve rektumda görülmüştür (1).

McKittrick-Wheelock sendromu villöz adenomun sebep olduğu, dehidratasyon, ciddi elektrolit imbalansı ve prerenal akut böbrek yetmezliği ile komplike hale gelen fazla miktarda sekretuar diare olarak tanımlanmıştır (6). Distal yerleşimli tümörün reabsorbsiyona olanak sağlayacak sağlam mukozal alan bırakmaması diare kliniğine katkıda bulunmaktadır. Etyoloji net olarak belirlenememişse de sekretuar villöz adenomlarda kabul gören hipotez; hipersekretuar durumun PGE2 ve cAMP yolakları üzerinden su ve elektrolit kaybına neden olduğu yönündedir. Siklooksijenaz inhibitörlerinin her iki yolağı da baskıladığı ve semptomları azalttığ gösterildiğinden İndometazinin bu gibi refrakter hipopotasermik villöz adenomlarda erken dönemde tercih edilebileceği ve efektif olduğunu belirten çalışmalar mevcuttur (1-8).

Büyük villöz adenomlarda bir diğer sorun endoskopik biopsilerin tanı için yetersiz kalabilmesidir. Sungeon ve ark (9) kolonoskopik yöntemle alınan biopsilerin \%50 oranında doğru tanı verdiğini ve 8 hastadan 1'inde beklenmeyen invaziv kanserle karşılaşıldığını söylemişlerdir. Bizim vakamızda 2013 'te alınan biyopsi sonuçlarında düşük dereceli displazi, 2018'de ise düşük dereceli displazi, yüksek dereceli displazi ve 1 odakta invaziv karsinom olarak raporlandi.

McKittrick-Wheelock sendromunun güncel tedavisi renal fonksiyonların ve elektrolit imbalansinın düzeltilmesinden sonra endoskopik veya cerrahi total tümör rezeksiyonu veya brakiterapidir. Tümörün yumuşak natürü, flat oluşu ve belirgin sınırlara sahip olmaması da endoskopik rezeksiyonu 
zorlaştırmaktadır. Brakiterapi ve endoskopik rezeksiyonun yüksek rekürrens oranları olması nedeniyle tedavi başarıları düşüktür $(2,7)$.

Cerrahi yöntem olarak transsfinkterik, transanal, transabdomnal veya transanal endoskopik ve minimal invaziv yaklaşımla tedavi edilmiş vakalar bulunmaktadır $(9,10,11)$. Yavaş ve benign seyirli olan bir hastalık için abdominoperineal rezeksiyon gibi ekstensif cerrahi yöntemler öncelikli planda düşünülmemelidir ancak vakamızda cerrahi planlama yapılırken hastalığın çok uzun bir segmenti $(24 \mathrm{~cm})$ çepeçevre tutması, dentat çizginin distaline protrude olması ve kolonoskopide alınan çoklu biopsilerden dentatline üzerinden alınan bir tanesinde invaziv karsinom raporlanması etkili oldu.

\section{SONUÇ}

6 yıldır mukuslu dışkılama şikyeti haricinde stabil olan hasta son birkaç aydır dehidratasyon, prerenal azotemi, elektrolit imbalansı ile komplike oldu. Bunun nedeni ilerleyen zamanla birlikte tümörün büyümesi veya displazi durumundaki olarak düşünülebilir..

\section{REFERANSLAR}

1. Konishi F, Morson BC. Pathology of colorectal adenomas: a colonoscopic survey. J Clin Pathol. 1982;35:830-841.

2. Popescu A, Orban-Schiopu A, Becheanu G, Diculescu M. McKittrick-Wheelock syndrome - a rare cause of acute renal failure. Rom J Gastroenterol 2005; 14: 63-66

3. Kagan MD, Schmidt K, Sangha G. Indomethacin therapy effective in a patient with depletion syndrome from secretory villous adenoma. BMJ Case Rep. 2017 Feb 10;2017.

4. Pheils MT. Villous tumors of the rectum. Dis Colon Rectum 1979; 22: 406-407.

5. Emerich J, Niemeyer C. The secreting villous adenoma as a rare cause of acute renal failure. Med Klin (Munich). 2002;15;97(10):619-623.

6. McKittrick LS, Wheelock FC., Jr Carcinoma of the colon. Charles C Thomas; Springfield, IL, 1954; pp.61-63.

7. Tuta LA, Boşoteanu M, Deacu M, Dumitru E. McKittrick Wheelock syndrome: a rare etiology of acute renal failure associated to well-differentiated
Sunduğumuz vaka; nadir görülen, pek çok klinisyenin diare ayırıcı tanısında göz önünde bulundurmadığı, klasik triadı tamamlamış McKittrick-Wheelock senrdromu idi. İncelemelerde rektosigmoid kolonun $24 \mathrm{~cm}$ 'lik segmentini kaplayan villöz adenoma bağlı ciddi elektrolit anomalileri ve dehidratasyonla karşıllaşıldı. Hastamızın 2013 yılında yapılan kolonoskopisinde düşük dereceli displazisi odakları olan 3cm'lik adenom, 2018 yılında 24 cm'lik segmenti kaplayan ve dentat hatta invaziv karsinom odakları içeren kitle şeklinde karşımıza çıktı. Eğer erken dönemde hasta ameliyatı kabul etseydi endoskopik rezeksiyon veya aşağ 1 anterior rezeksiyon veya intersfinkterik rezeksiyon yapılarak hastanın ostomi bağımlılı̆g 1 oluşmadan barsak devamlılığı sağlanabilecekti.

Nadir görülen, tedavisiz kaldığ 1 taktirde $\% 100$ mortal seyreden, cerrahi veya endoskopik veya ablatif yöntemlerle total eksize veya destrükte edildiği taktirde kür sağlanabilen, biopsi sonuçlarının yetersiz kalabileceği bir adenokarsinom vakasını sunduk

adenocarcinoma (G1) arising within a villous adenoma. Rom J Morphol Embryol. 2011;52:11531156.

8. Jacob H, Schlondorff D, St Onge G, Bernstein LH. Villous adenoma depletion syndrome. Evidence for a cyclic nucleotide-mediated diarrhea. Dig Dis Sci. $1985 \mathrm{Jul} ; 30(7): 637-41$.

9. Cho SD, Herzig DO, Douthit MA, Deveney KE. Treatment strategies and outcomes for rectal villous adenoma from a single-center experience. Arch Surg. 2008 Sep;143(9):866-70.

10. Koning GG, Rensma PL, van Milligen de Wit AW, van Laarhoven CJ. In-one-continuity rectal excision and anal mucosectomy of a giant villous adenoma: an alternative surgical approach. Case Rep Gastroenterol. 2008 May 24;2(2):175-80

11. van der Pool AEM, de Graaf EJR, Vermaas M, Barendse RM, Doornebosch PG. McKittrick Wheelock Syndrome Treated by Transanal Minimally Invasive Surgery: A Single-Center Experience and Review of the Literature. J Laparoendosc Adv Surg Tech A. 2018 Feb;28(2):204-208 